The bridge was severely tested by Gen. Hutchinson, the Government Inspector of Railways, in February of this year. Five locomotive engines of 72 tons weight each were placed on the large spans and run over them at considerable speed. This weight of 360 tons for each of the $245^{\prime}$ spans will never be reached in the working of the railway, 162 tons being the greatest load resulting on each span from the heaviest goods train. Under the test load the deflection of any of the spans did not exceed the calculated limit, and the lateral movement during the passage of trains was but trifling.

On June I the bridge was opened for ordinary traffic, and it is now daily crossed by numerous and heavy trains. For the North British Railway Company and the travelling public its completion is of very great importance. But the work must have a still greater importance in the eyes of engineers and those interested in the practical application of scientific principles, as many new methods to overcome formidable difficulties were successfully carried out, some of which might with advantage be used in similar structures.

A. GROTHE

\section{THE NORWEGIAN NORTH ATLANTIC EXPEDITION}

THE expedition left Bergen on June I5, and proceeded without interruption to the Westfjord, in Nordland, where we had our first station. A temperature-series was here taken with Negretti and Zambra's new deep-sea thermometer, which showed $10^{\circ} 7 \mathrm{C}$. on the surface, a minimum of $4^{\circ} 4$ in a depth of 40 fathoms, and $6^{\circ} .5$ at the bottom in 340 fathoms. The Vöringen stopped some hours at Tromsö to take on board a pilot, and proceeded to the Altenfjord, where we found $7^{\circ} \cdot 3$ at the surface, a minimum of $2^{\circ} 7$ in a depth of 100 fathoms, and $3^{\circ} 9$ in 220 fathoms at bottom. From Alten we went to Hammerfest, where we stayed two days. Our next stations were in the Porsangexfjord and in the Tanafjord. On all these stations we dredged and trawled with good success. On June 26 we were lying at Wardö, where Capt. Wille made magnetical observations of force and inclination. The declination was determined the day before off the coast by going round with the ship, and taking bearings of the sun on different courses. On June 27 we put to sea on an eastward course. The barometer was falling rapidly, and at midnight the wind and sea got so heavy, that the ship was put with the stem against the wind, and we were lying almost still. This situation lasted till the next night, when we again proceeded on our course, but very slowly, the ship pitching heavily, and the wind being constantly ahead. In this manner we found $0^{\circ} \mathrm{C}$. at the sea bottom, in about $71^{\circ} 30^{\prime} \mathrm{N}$. and $36^{\circ} 30^{\prime} \mathrm{E}$. from Green wich. We then sailed northwards and westwards, and passed the said bottom temperature several times, so that I am now able to give its situation pretty accurately in the chart. The northern part of this zero line forms a bay east of Bear (Cherry) Island, where the warmer water reaches a higher latitude, and runs close to the east side of that island, where we for the first time observed the polar ice. The temperature-series showed the accuracy of Weyprecht's observations, that the colder Polar water edges itself along the bottom from the east and north, and the warm Atlantic water runs out in a similar edge in the contrary direction towards Novaya Zemlya and Franz-Joseph Land. On July 4 we were at Bear Island, on the south-east side. We were happy to find the sky almost perfectly clear, a ratber rare occurrence on this island. The ship was anchored outside the open coast, and we went on shore at the mouth of a little river, in the vicinity of which there stands a hut, which has been the abode of wintering parties. Here we deposited the mail which we brought for the Dutch polar exnedition in the Wilhem Barentz schooner. The place was marked with a flag, and the letters, \&c., dug down, inclosed in an outer wooden and an inner sheet-iron soldered box. I took a tour upon the nearest hills, collected some rock specimens, and measured the altitude of the highest peak on Bear Island, Mount Misery. The calculation gave me a height of 1,787 English feet, a result which I regard as very accurate. After dinner we weighed and proceeded to the south-west; crossed, the following day, the zero line of bottom temperature on the bank between Bear Island and Norway, sounded in 1,024 fathoms on July 6 in lat. $73^{\circ} 6^{\prime} \mathrm{N}$, , long. $11^{\circ} 56^{\prime}$ E.; we went then east-south-eastwards, crosșed again the zero temperature line, and shaped our course for Hammerfest, where we arrived on the 8th. The ship is now cleaned; we take in coal, and expect to be ready to sail on a westward cruise in three days. Our first cruise has yielded thirty-eight soundings, seventeen temperature series, ten dredgings, and seven trawlings, all successful, New species of animals have been found by our zoologists. Negretti and Zambra's newest reversible deep-sea thermometer has done us great service; the instrument has, almost without exception, worked very well. I have constantly compared its readings from the bottom with the reading of the Casella, Bucbanan's improved form, and found a very close agreement. As I supposed, the wooden box which carries the thermometer gets watersoaked after a few experiments in a few hundred fathoms, so that it no longer floats, but this is no drawback, as the lead rushes down so fast that the thermometer always keeps its upright situation till it reaches the bottom, and it never requires more than three minutes for a perfect accommodiation to $O^{\prime} I$ of a degree. I therefore regard this instrument as a very important improvement, and feel much obliged to the inventors and makers.

Hammerfest, July ro

H. MOHN

\section{THE TASTMETER}

TR. EDISON has applied the principle of his carbon telephone to a new instrument which is said to be a measurer of infinitesimal pressure. The principle is the variation of the electric resistance of a carbon button due to variation of pressure, and the instrument is said to be an extremely delicate thermoscope. We have not yet, however, received any authentic account of its performance or of its accuracy, but its ingenuity certainly deserves a description, for which we are indebted to the Scientific Anterican.

It is the outcome of Mr. Edison's carbon telephone. Having experimented with diaphragms of various thicknesses, he ascertained that the best results were secured by using the thicker diaphragms. At this stage, however, he experienced a new difficulty. So sensitive was the carbon button to changes of condition, that the expansion of the rubber telephone handle rendered the instrument inarticulate, and finally inoperative. Iron bandles were substituted with a similar result, but with the additional feature of musical and creaky tones distinctly audible in the receiving instrument. These sounds Mr. Edison attributed to the movement of the molecules of iron among themselves during expansion. He calls them "molecular music." To avoid these disturbances in the telephone, the handle was dispensed with; but it had done a great service in revealing the extreme sensitiveness of the carbon button, and this discovery opened the way for the invention of the new and wonderful instrument.

The micro-tasimeter is represented in perspective in Figs. I and 2, in section in Fig. 3, and the plan upon which it is arranged in the electric circuit is shown in Fig. 4.

The instrument consists essentially of a rigid iron frame for holding the carbon button, which is placed between 
tiro platinum surfaces, one of which is fixed and the other movable, and in a device for holding the object to be tested, so that the pressure resulting from the expansion of the object acts upon the carbon button.

Two stout posts $A, B$, project from the rigid base piece, C. A vulcanite disc, $D$, is secured to the post, $A$, by the platinum-headed screw, E, the head of which rests in the bottom of a shallow circular cavity in the centre of the disc. In this cavity, and in contact with the head of the screw, $\mathrm{E}$, the carbon button, $\mathrm{F}$, is placed. Upon the outer face of the button there is a disc of platinum foil, which is in electrical communication with the battery. A metallic

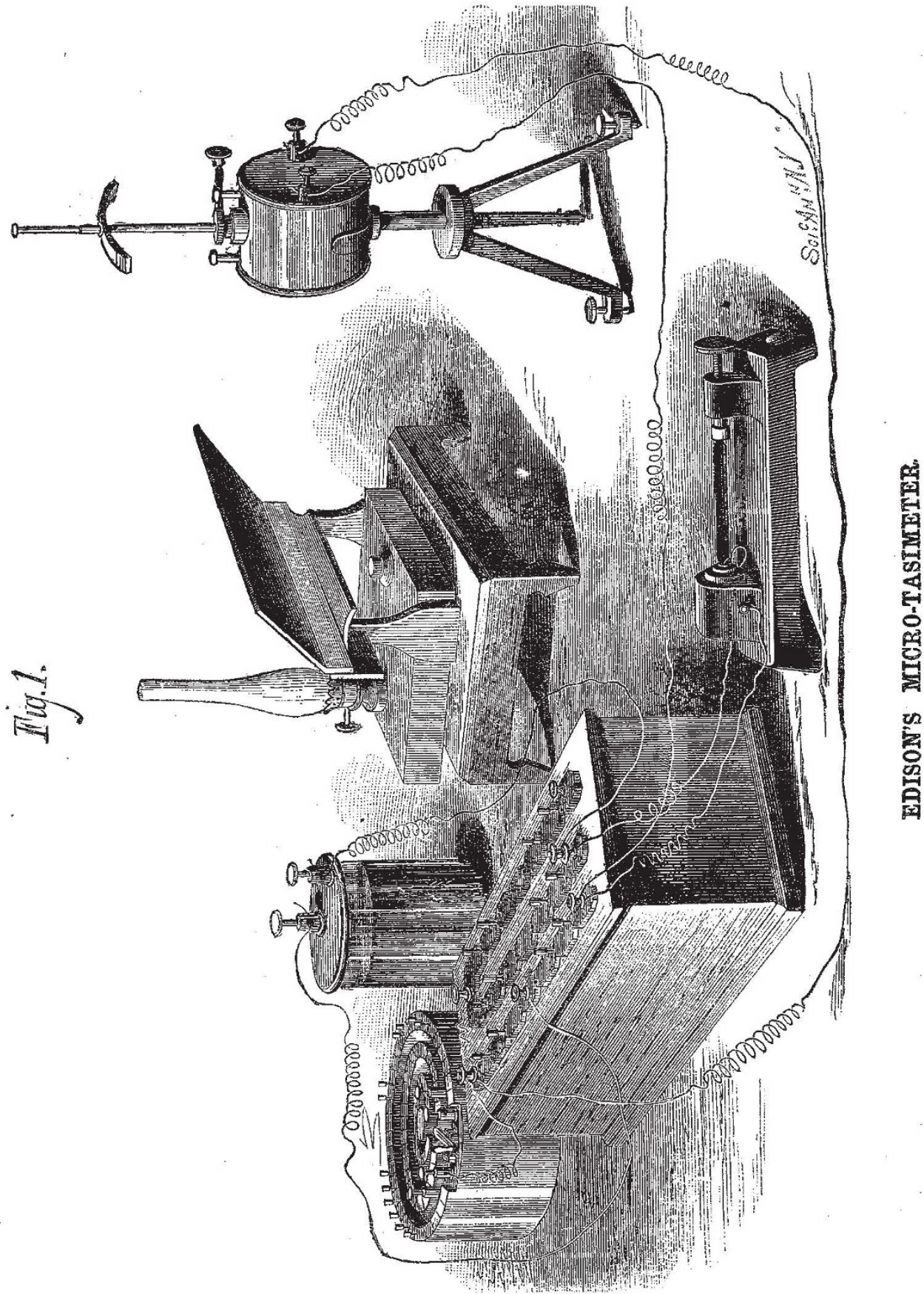

cup, G, is placed in contact with the platinum disc to receive one end of the strip of whatever material is employed to operate the instrument.

The post, $\mathrm{B}$, is about four inches from the post, $\mathrm{A}$, and contains a screw-acted follower, $\mathrm{H}$, that carries a cup, I, between which and the cup, $G$, is placed a strip of any substance whose expansibility it is desired to crhibit.
The post, $A$, is in electrical communication with a galvanometer, and the galvanometer is connected with the battery. The strip of the substance to be tested is put under a sniall initial pressure, which deflects the galvanometer needle a few degrees from the neutral point. When the needle comes to rest its position is noted. The slightest subsequent expansion or contraction of the strip will be 
indicated by the movement of the galvanometer needle. A thin strip of hard rubber, placed in the instrument, exhibits extreme sensitiveness, being expanded by heat from the hand, so as to move through several degrees the needle of a very ordinary galvanometer, which is not affected in the slightest degree by a thermopile facing and near a red-hot iron. The hand, in this experiment, is held a few inches from the rubber strip. A strip of mica is sensibly affected by the heat of the hand, and a strip of gelatin, placed in the instrument, is instantly expanded by moisture from a dampened piece of paper held two or three inches away.

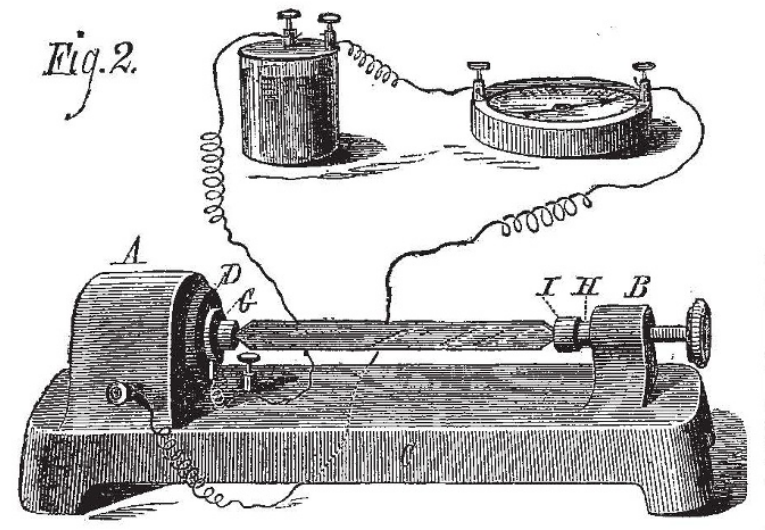

For these experiments the instrument is arranged as in Fig. 2, but for more delicate operations it is connected with a Thomson's reflecting galvanometer, and the current is regulated by a Wheatstone's bridge and a rheostat, so that the resistance on both sides of the galvanometer is equal, and the light-pencil from the reflector falls on $0^{\circ}$ of the scale. This arrangement is shown in Fig. I, and the principle is illustrated by the diagram, Fig. 4. Here the galvanometer is at $g$, and the instrument which is at $i$ is adjusted, say, for example, to ten ohms resistance. At $a, b$, and $c$ the resistance is the same. An increase or

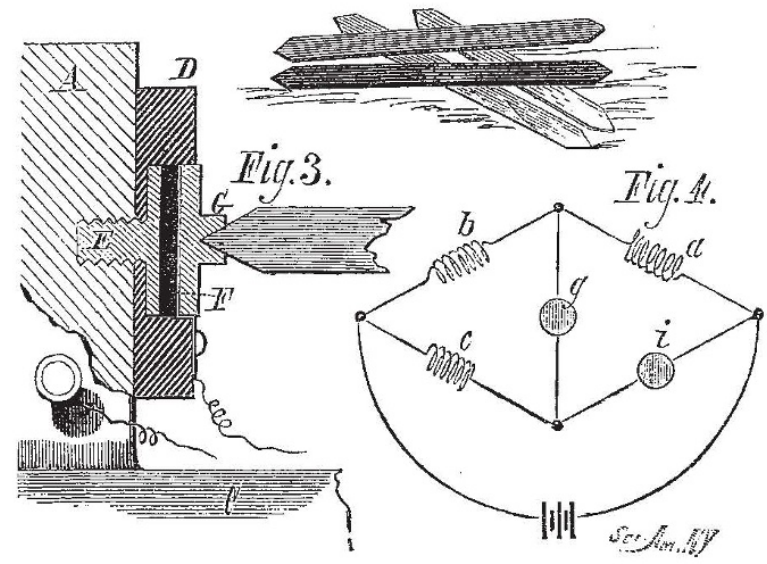

diminution of the pressure on the carbon button by an infinitesimal expansion or contraction of the substance under test is indicated on the scale of the galvanometer.

The carbon button may be compared to a valve, for when it is compressed in the slightest degree its electrical conductivity is increased, and when it is allowed to expand it partly loses its conducting power.

The heat from the hand held six or eight inches from a strip of vulcanite placed in the instrument-when arranged as last described-is sufficient to deflect the galvanometer mirror so as to throw the light-beam completely off the scale. A cold body placed near the vulcanite strip will carry the light-beam in the opposite direction.

Pressure that is inappreciable and undiscoverable by other means is distinctly indicated by this instrument.

Mr. Edison proposes to make application of the principle of this instrument to numberless purposes, among which are delicate thermometers, barometers, and hygrometers. He expects to indicate the heat of the stars and to weigh the light of the sun.

\section{KEW GARDENS REPORT}

SIR JOSEPH HOOKER'S Annual Report for 1877 is more than usually bulky, extending to fifty-three pages. The report opens with the number of visitors admitted to the gardens during the year, which amounted to 687,972 , a great excess over those of the preceding year. The points of public interest first treated of by the Director are, as might have been supposed, those affecting the agitation to remove the boundary wall along the Richmond Road and to open the gardens at an earlier hour. These points have been so freely discussed of late in the public press that we need do no more than refer to them. Referring to his visit to North America, Sir Joseph pays a high tribute to the intelligence and courtesy of the people. He says: "I cannot adequately express my sense of the liberality with which travelling facilities and hospitalities of all kinds were accorded to me by public companies and private individuals wherever I went in America. The fact of my being connected with this establishment [Kew] was a recognised passport, and this even in the remote settlements of the Far West, for I found a reading people everywhere, few of whom had not heard of Kew Gardens. In the Northern States of America the progress of science, and of institutions for the instruction of the people in science, occupy a prominent place in the cheap illustrated periodical literature of the masses; and nowhere on the globe is this literature better or so universally read as in the States. It is hence not wonderful that the progress of such establishments as Kew, the British Museum, South Kensington Museum, \&c., should be better known amongst all classes of the people there than they are in the United Kingdom generally, and so I found it."

Under the head of "Interchange of Plants and Seeds," as also under that of "Official Correspondence," a vast deal of information is gathered together on the acclimatisation, extended cultivation, or further development of useful plants. Thus we find the ipecacuanha (Cephaellis ipecacuanha), a native of Brazil, has been distributed from the Calcutta Botanic Garden to Ceylon, Singapore, Burmah, and the Andamans. Dr. King, however, does not take a very hopeful view of its ultimate success in India, partly on account of its peculiarly slow growth, which tends to prevent its cultivation being taken up with spirit by European planters, and partly on account of its insignificant appearance, which does not even excite interest. among the planters. Sir Joseph suggests it as "worthy of consideration whether the Indian government would not do well to establish a nursery in some part of our Indian possessions, with the tropical climatic conditions necessary for its growth." In connection with this subject, considering the great value of the ipecacuanha in cases of dysentery, it is satisfactory to note that there seems some prospect of its cultivation being attempted in the native states of Perak, where the soil and climate are considered to be well adapted to its requirements. Regarding the prophylactic virtues of Eucalyptus globulus - a subject which has been to some extent ventilated in our own columns-the experiences of the Kew authorities do not throw any further light on it. As valuable timber-trees, however, there can be no doubt that many of the species of Eucalyptus will prove most valuable. Sir Joseph says:-"The merits of the numerous species of 